• 研究报告・

\title{
齐云山国家级自然保护区蝴蝶群落多样性
}

\author{
黄敦元 ${ }^{*}$ 黄世贵 ${ }^{3}$ 王建皓 ${ }^{3}$ 李红英 ${ }^{1}$ 窦飞越 ${ }^{1}$ \\ 张 可 ${ }^{1}$ 朱祥龙 $^{3}$ 马方舟 ${ }^{2 *}$ \\ 1 (重庆师范大学生命科学学院媒介昆虫重点实验室, 重庆 401331) \\ 2 (生态环境部南京环境科学研究所/国家环境保护生物安全重点实验室, 南京 210042) \\ 3 (江西省齐云山国家级自然保护区管理局, 江西赣州 341300)
}

摘要: 为研究齐云山国家级自然保护区蝴蝶群落多样性, 2016年4月至2018年10月, 作者在江西齐云山国家级自然 保护区不同生境选取 5 条长 $2,000 \mathrm{~m}$ 的固定样线进行了每年6次、累计18次的蝶类多样性调查。共记录到蝴蝶6,946 只, 隶属5科106属189种, 其中东洋界种类是优势类群(183种, 占总种数的96.8\%)。蛱蝶科的种类最多 $(81$ 种, 占 $42.9 \%)$, 其物种丰富度指数 $(R=8.42)$ 、多样性指数 $\left(H^{\prime}=3.21\right)$ 和优势度指数 $(D=0.60)$ 较高, 属于优势类群。齐云山 国家级自然保护区蝴蝶个体数从 4 月开始逐渐增加, 到6-7月基本稳定并维持到10月; 物种数在4-10月基本稳定, 具有较高的多样性指数。保护区内不同生境观测样线的蝴蝶种类和数目有较大的差异: 针阔混交林的桐江样线蝴 蝶种类 $(126$ 种, 占 $66.7 \%)$ 及数目 $(1,945$ 只, 占 $28.2 \%)$ 最多, 其物种丰富度指数 $(R=16.51)$ 最高; 常绿阔叶林的上十 八垒样线蝴蝶数目相对较少 (905只, 占 $13.0 \%$ ), 但是蝴蝶种类相对较多(103种, 占 $54.5 \%)$, 所以多样性指数 $\left(H^{\prime}=\right.$ 3.93)和优势度指数 $(D=0.85)$ 较高; 农田和果园生境的三角潭样线由于生境简单且人为干扰强度较大, 蝴蝶物种数 相对较少(97种, 占51.3\%)。研究表明: 江西省齐云山国家级自然保护区的蝴蝶区系组成以东洋区为绝对主导的分 布类型, 蝴蝶群落多样性与生境类型有明显的相关性, 季节性的农耕活动、除草剂农药的大量使用、寄主植物的 大量砍伐等人类活动威胁到蝴蝶的多样性及蝶类群落结构的稳定性。

关键词: 齐云山国家级自然保护区; 蝴蝶多样性; 区系; 物种组成

\section{Diversity of butterfly communities in the Qiyunshan National Nature Reserve}

Dunyuan Huang ${ }^{1 *}$, Shigui Huang ${ }^{3}$, Jianhao Wang ${ }^{3}$, Hongying $\mathrm{Li}^{1}$, Feiyue Dou ${ }^{1}$, Ke Zhang ${ }^{1}$, Xianglong Zhu ${ }^{3}$, Fangzhou $\mathrm{Ma}^{2 *}$

1 Chongqing Key Laboratory of Vector Insects, College of Life Sciences, Chongqing Normal University, Chongqing 401331

2 Nanjing Institute of Environmental Sciences, Ministry of Ecology and Environment; National Key Laboratory of Biosafety, Ministry of Ecology and Environment, Nanjing 210042

3 Administration of Qiyunshan National Nature Reserve in Jiangxi, Ganzhou, Jiangxi 341300

Abstract: To study the diversity of butterfly community, from April 2016 to October 2018, a butterfly diversity survey was conducted along five fixed-sample transects of 2,000 m each in different habitats within the Qiyunshan National Nature Reserve of Jiangxi Province. Transects were sampled six times per year and 18 times in total. A total of 6,946 butterflies was recorded, belonging to 189 species of 106 genera under 5 families, of which the Oriental was dominant group (183 species, 96.8\%). The family Nymphalidae had the largest number of species (81 species, $42.9 \%)$ with a high richness index $(R=8.42)$, diversity index $\left(H^{\prime}=\right.$ 3.21), and dominance index $(D=0.60)$, suggesting this was the dominant group. The number of butterflies in Qiyunshan National Nature Reserve gradually increased from April to May, stayed relatively stable from June to July, and remained until October. From April to October, the number of butterfly species

收稿日期: 2019-12-31; 接受日期: 2020-06-28

基金项目: 国家重点研发计划(2018YFC0507206)

* 共同通讯作者 Co-authors for correspondence. E-mail: huangdunyuan@126.com; mfz@nies.org 
was basically stable, with a high diversity index. However, there were significant differences in the species composition and distribution of butterflies across various habitats in the protected area. The Tongjiang transect of the mixed forest had the greatest number of butterfly species (126 species, 66.7\%), the highest species richness index $(R=16.51)$, and the highest overall abundance $(n=1,945,28.2 \%)$. In the evergreen broad-leaved forest of the Shangshibalei transect, a smaller abundance of butterflies was observed ( $n=905,13.0 \%$ ), but there were more butterfly species (103 species, 54.5\%), with a higher diversity index $\left(H^{\prime}=3.93\right)$ and dominance index $(D=0.85)$. The number of butterfly species in the farmland/orchard habitat of the Sanjiaotan transect was relatively small (97 species, 51.3\%), likely due to its simple habitat and high intensity of human disturbance. Our results show that the composition of butterfly fauna of Qiyunshan National Nature Reserve in Jiangxi Province is dominated by species in the Oriental realm. The diversity of butterfly communities has a clear correlation with the type of habitat. Intensity of human activities, such as seasonal farming, heavy use of herbicides and pesticides, and massive cutting of host plants, threatens the diversity of butterflies and the stability of butterfly community structure.

Key words: Qiyunshan National Nature Reserve; butterfly diversity; fauna; species composition

生物多样性观测是环境观测的重要组成部分, 是客观了解生物多样性现状、科学开展生物多样性 保护与管理的基础工作(Xu et al, 2017)。不仅可为管 理者提供环境变化信息, 也可以监督、评估管理机 构在推动保护工作时是否达到预期效果，从而为制 定保护计划和管理措施提供依据。

昆虫类群是生物多样性的重要组成部分, 生态 位分布广, 在自然生态系统的正常运行过程中扮演 着重要的角色(尤民生, 1997; Samways, 2005)。近年 来全球气候变化、人类活动干扰、生态系统退化等 因素直接或间接威胁到昆虫的生存和发展, 因此, 研究影响昆虫多样性的因素并采取相应的保护措 施, 对维持特定生态系统的稳定性具有重要意义。诸 多研究表明, 温度和湿度等气候因子(Maveety et al, 2013; Wang et al, 2014)、昆虫所处特定生境下的植 被组成及丰富度(Márialigeti et al, 2016)、景观生态 类型及结构异质性(Donkersley et al, 2014; Ohwaki et al, 2015)、栖息地的破碎化及大量农药除草剂的 使用(Rands et al, 2010; Tsvetkov et al, 2017; Siviter et al, 2018)等因素均对昆虫多样性有一定的影响。

蝴蝶类群物种多样性丰富、分布范围广, 对生 境条件具有较强的专一性, 对所处生态系统健康状 况与气候变化情况极其敏感(Kitching et al, 2000; 顾伟等, 2015; 刘素群等, 2017; 马方舟等, 2018), 因此常被作为环境指示生物类群(Kremen, 1992; 李 密等, 2011; 梅杰等, 2015; 洪雪萌等, 2018)。蝴蝶种 群的时空动态和群落结构特征演变能够快速、有效 地反映环境质量、生态系统健康程度以及人类活动
干扰等生态环境状况(Nowicki et al, 2008; 李佳琳 等, 2011; Mair et al, 2012), 其多样性观测数据可作 为各类型生态系统的重要评价依据(晏华等, 2006; 马方舟等, 2018)。

江西省齐云山国家级自然保护区地处南岭山 地北坡, 属中亚热带东部湿润型季风气候区, 蝴蝶 资源比较丰富, 但是目前系统的研究较少, 蝴蝶多 样性的现状及变化趋势不明确, 因此在该地区开展 蝴蝶类群的多样性研究十分必要。

\section{研究区域和研究方法}

\section{1 研究区域概况}

齐云山是罗霄山脉南端山脉主峰, 海拔2,061.3 $\mathrm{m}$, 为赣南地区第一高峰。江西省齐云山国家级自 然保护区地理坐标为 $113^{\circ} 54^{\prime}-114^{\circ} 07^{\prime} \mathrm{E}, 25^{\circ} 41^{\prime}-$ $25^{\circ} 54^{\prime} \mathrm{N}$, 总面积 17,105 ha, 森林覆盖率达 $97.6 \%$, 其中核心区 $97.8 \%$, 缓冲区 $98.1 \%$, 实验区 $96.7 \%$ (刘 小明等, 2010)。保护区内现有高等植物2,843种, 其 中被子植物 169 科 830 属2,402种。该保护区植被具明 显的水平和垂直分布特征: 水平分布上, 地带性植 被中亚热带东部湿润性常绿阔叶林分布最广、面积 最大, 针叶林则主要分布在陡峭的山脊、梁顶, 林 下灌木和草本层植物的分布也表现出水平方向上 的差异。植被垂直分布规律不甚明显, 但仍可划成 毛竹(Phyllostachys heterocycla)林(400-1,100 m)、常 绿阔叶林 (400-1,200 m)、常绿落叶阔叶混交林 (1,000-1,500 m)、针阔混交林 $(1,300-1,600 \mathrm{~m}) 、 山$ 顶 矮林 $(1,600-1,800 \mathrm{~m})$ 、山地草甸(1,800 $\mathrm{m}$ 以上) 几个 
垂直带(陈言柳等, 2019)。

\section{2 研究方法}

\subsection{1 样地设置}

野外调查方法采取样线法(马方舟等, 2018), 即在保护区境内沿公路、小径、步道共设置5条2,000 $\mathrm{m}$ 长的样线(表1), 样线生境主要包括常绿阔叶林、 针阔混交林、农田和果园等。样线法及生境类型的 界定主要参考《生物多样性观测技术导则: 蝴蝶》 (HJ710.9-2014)。

\subsection{2 调查时间及方法}

于2016-2018年的4-10月进行调查，每年6次, 每次间隔至少20天(马方舟等, 2018)。在晴朗和风力 不大(三级以下)的白天9:00-17:00进行观测。观测时 3-4人一组, 以 $1.0-1.5 \mathrm{~km} / \mathrm{h}$ 的速度沿固定样线匀速 前进，记录样线左右各 $2.5 \mathrm{~m}$ 、上方 $5 \mathrm{~m}$ 、前方 $5 \mathrm{~m}$ 范 围内见到的所有蝴蝶的种类和数量。对现场难以确 定的物种先记录其个体数量, 采集部分标本并尽可 能拍摄其生态照片。将采集的蝴蝶标本用三角纸袋 包装好，标注采集时间、生态照编号、地点等信息， 带回实验室及时对照相关参考资料(周尧，1994; 武 春生, 2010; 袁景西等, 2015)进行鉴定并完善观测 记录表数据。

\subsection{3 数据分析}

根据齐云山国家级自然保护区蝴蝶群落的特 点及3年的观测数据, 按照群落生态学的统计方法, 采用物种丰富度指数 $(R)$ (马克平和刘玉明, 1994)、 Shannon-Wiener指数 $\left(H^{\prime}\right)$ (Shannon, 1948)、Pielou均 匀度指数 $(J)$ (Pielou, 1966) 和Berger-Parker优势度指 数 $(D)$ (Berger \& Parker, 1970), 运用Excel、SPSS等
软件分析蝴蝶的群落结构和物种多样性。

$$
\begin{aligned}
& R=(S-1) / \ln N \\
& H^{\prime}=-\sum_{i=1}^{S} P_{i} \ln P_{i} \\
& J=H^{\prime} / H_{\text {max }}, \quad H_{\text {max }}=\ln S \\
& \mathrm{D}=N_{\text {max }} / N
\end{aligned}
$$

其中, $S$ 为物种数; $N$ 为群落中的总个体数; $P_{i}=N_{i} / N$; $N_{i}$ 为第 $i$ 种的个体数; $H_{\max }$ 为给定物种完全均匀时的 群落多样性指数; $N_{\max }$ 为优势类群的数量。

\section{结果}

\section{1 蝴蝶群落的组成}

2016-2018年，江西省齐云山国家级自然保护 区共观测到蝴蝶个体6,946只，归属5科106属189种 (附录1), 其中蛱蝶科种类最多(81种，占42.9\%), 其 次是弄蝶科 (43 种，占 $22.7 \%$ )、灰蝶科 (30 种，占 $15.9 \%)$ 、凤蝶科(20种，占 $10.6 \%)$ 、粉蝶科(15种, 占7.9\%) (表2)。

\section{2 蝴蝶的多样性}

齐云山国家级自然保护区的蝴蝶群落中(表2), 蛱蝶科物种丰富度指数 $(R=8.42)$ 、多样性指数 $\left(H^{\prime}=\right.$ $3.21)$ 和优势度指数 $(D=0.60)$ 较高, 属于优势类群。 丰富度指数和多样性指数从高到低依次是: 蛱蝶科、 灰蝶科、弄蝶科、粉蝶科和凤蝶科; 均匀度指数从 高到低依次是: 灰蝶科、弄蝶科、粉蝶科、凤蝶科 和蛱蝶科; 优势度指数从高到低依次是: 蛱蝶科、

\begin{tabular}{|c|c|c|c|c|c|}
\hline $\begin{array}{l}\text { 样线 } \\
\text { Transect }\end{array}$ & $\begin{array}{l}\text { 经纬度 } \\
\text { Locality }\end{array}$ & $\begin{array}{l}\text { 海拔 } \\
\text { Elevation (m) }\end{array}$ & $\begin{array}{l}\text { 主要生境类型 } \\
\text { Major habitat type }\end{array}$ & $\begin{array}{l}\text { 郁闭度(平均值 } \pm \text { 标准差) } \\
\text { Canopy density (mean } \pm \mathrm{SD})\end{array}$ & $\begin{array}{l}\text { 人类干扰 } \\
\text { Human disturbance }\end{array}$ \\
\hline $\begin{array}{l}\text { 上十八垒 } \\
\text { Shangshibalei }\end{array}$ & $\begin{array}{l}25.87^{\circ} \mathrm{N} \\
114.03^{\circ} \mathrm{E}\end{array}$ & $925-1,420$ & $\begin{array}{l}\text { 常绿阔叶林 } \\
\text { Evergreen broad-leaved forest }\end{array}$ & $0.95 \pm 0.12$ & $\begin{array}{l}\text { 季节性旅游 } \\
\text { Seasonal tourism }\end{array}$ \\
\hline $\begin{array}{l}\text { 下十八垒 } \\
\text { Xiashibalei }\end{array}$ & $\begin{array}{l}25.83^{\circ} \mathrm{N} \\
114.03^{\circ} \mathrm{E}\end{array}$ & $671-719$ & $\begin{array}{l}\text { 常绿阔叶林加河流 } \\
\text { Evergreen broad-leaved forest and river }\end{array}$ & $0.55 \pm 0.15$ & $\begin{array}{l}\text { 除草剂的使用 } \\
\text { Herbicide application }\end{array}$ \\
\hline $\begin{array}{l}\text { 桐江 } \\
\text { Tongjiang }\end{array}$ & $\begin{array}{l}25.82^{\circ} \mathrm{N} \\
114.05^{\circ} \mathrm{E}\end{array}$ & 563-614 & $\begin{array}{l}\text { 针阔混交林 } \\
\text { Mixed wood }\end{array}$ & $0.75 \pm 0.11$ & $\begin{array}{l}\text { 基本没有 } \\
\text { Almost none }\end{array}$ \\
\hline $\begin{array}{l}\text { 鸡公坝 } \\
\text { Jigongba }\end{array}$ & $\begin{array}{l}25.82^{\circ} \mathrm{N} \\
114.08^{\circ} \mathrm{E}\end{array}$ & $607-827$ & $\begin{array}{l}\text { 针阔混交林 } \\
\text { Mixed wood }\end{array}$ & $0.68 \pm 0.13$ & $\begin{array}{l}\text { 基本没有 } \\
\text { Almost none }\end{array}$ \\
\hline $\begin{array}{l}\text { 三角潭 } \\
\text { Sanjjiaotan }\end{array}$ & $\begin{array}{l}25.79^{\circ} \mathrm{N} \\
114.11^{\circ} \mathrm{E}\end{array}$ & 369-438 & $\begin{array}{l}\text { 农田和果园 } \\
\text { Farmland and orchard }\end{array}$ & $0.45 \pm 0.16$ & $\begin{array}{l}\text { 除草剂的使用 } \\
\text { Herbicide application }\end{array}$ \\
\hline
\end{tabular}
凤蝶科、粉蝶科、灰蝶科和弄蝶科。

表1 齐云山国家级自然保护区不同样线的基本信息

Table 1 Basic information of different transects in the Qiyunshan National Nature Reserve 
表2 齐云山国家级自然保护区蝴蝶群落多样性指数

Table 2 Diversity indices of butterfly community in the Qiyunshan National Nature Reserve

\begin{tabular}{lllllll}
\hline $\begin{array}{l}\text { 科名 } \\
\text { Family }\end{array}$ & $\begin{array}{l}\text { 属数 } \\
\text { No. of genera }\end{array}$ & $\begin{array}{l}\text { 物种数 } \\
\text { No. of species }\end{array}$ & $\begin{array}{l}\text { 丰富度指数 } \\
\text { Richness index }\end{array}$ & $\begin{array}{l}\text { 多样性指数 } \\
\text { Diversity index }\end{array}$ & $\begin{array}{l}\text { 均匀度指数 } \\
\text { Evenness index }\end{array}$ & $\begin{array}{l}\text { 优势度指数 } \\
\text { Dominance index }\end{array}$ \\
\hline 凤蝶科 Papilionidae & 7 & 20 & 2.00 & 1.65 & 0.92 & 0.24 \\
粉蝶科 Pieridae & 10 & 15 & 2.95 & 2.06 & 0.94 & 0.15 \\
蛱蝶科 Nymphalidae & 38 & 81 & 8.42 & 3.21 & 0.88 & 0.60 \\
灰蝶科 Hesperiidae & 24 & 30 & 6.76 & 3.11 & 0.98 & 0.05 \\
弄蝶科 Hesperiidae & 27 & 43 & 6.65 & 3.10 & 0.95 & 0.05 \\
\hline
\end{tabular}

表3 齐云山国家级自然保护区不同样线蝴蝶群落多样性指数

Table 3 Diversity indices of butterfly community in different transects of the Qiyunshan National Nature Reserve

\begin{tabular}{|c|c|c|c|c|c|c|}
\hline $\begin{array}{l}\text { 样线 } \\
\text { Transect }\end{array}$ & $\begin{array}{l}\text { 物种数 } \\
\text { No. of species }\end{array}$ & $\begin{array}{l}\text { 个体数 } \\
\text { No. of individuals }\end{array}$ & $\begin{array}{l}\text { 丰富度指数 } \\
\text { Richness index }\end{array}$ & $\begin{array}{l}\text { 多样性指数 } \\
\text { Diversity index }\end{array}$ & $\begin{array}{l}\text { 均匀度指数 } \\
\text { Evenness index }\end{array}$ & $\begin{array}{l}\text { 优势度指数 } \\
\text { Dominance index }\end{array}$ \\
\hline $\begin{array}{l}\text { 上十八垒 } \\
\text { Shangshibalei }\end{array}$ & 103 & 905 & 14.98 & 3.93 & 0.85 & 0.03 \\
\hline $\begin{array}{l}\text { 下十八垒 } \\
\text { Xiashibalei }\end{array}$ & 88 & 1,189 & 12.29 & 3.62 & 0.81 & 0.04 \\
\hline $\begin{array}{l}\text { 桐江 } \\
\text { Tongjiang }\end{array}$ & 126 & 1,945 & 16.51 & 3.80 & 0.79 & 0.05 \\
\hline $\begin{array}{l}\text { 鸡公坝 } \\
\text { Jigongba }\end{array}$ & 108 & 1,449 & 14.70 & 3.90 & 0.83 & 0.03 \\
\hline $\begin{array}{l}\text { 三角潭 } \\
\text { Sanjiaotan }\end{array}$ & 97 & 1,458 & 13.19 & 3.22 & 0.70 & 0.09 \\
\hline
\end{tabular}
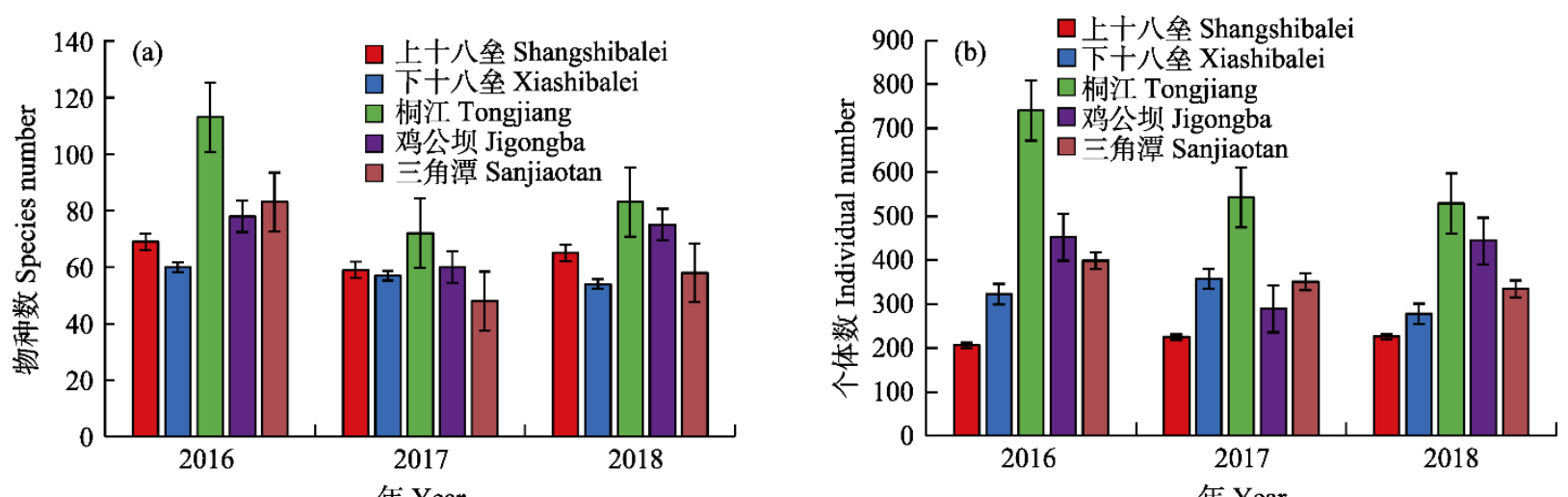

图1 齐云山国家级自然保护区不同样线蝴蝶物种数(a)和个体数(b)的年动态(平均值 \pm 标准差)

Fig. 1 Fluctuation of butterfly species (a) and individuals (b) in different transects of the Qiyunshan National Nature Reserve (mean $\pm \mathrm{SD})$

\section{3 不同生境类型的蝴蝶多样性}

由表3、图1可知, 不同生境的观测样线中蝴蝶 的种类和数目有较大的差异。5条观测样线中, 针阔 混交林的桐江样线蝴蝶种类和数目(3年累计观测 126 种 1,945 只, 分别占总种数和总个体数的 $66.7 \%$ 和 $28.2 \%)$ 最多，其物种丰富度指数 $(R=16.51)$ 最高。 常绿阔叶林的上十八垒样线蝴蝶个体数目较少(3年 累计观测到 905 只, 占 $13.0 \%$ ), 但是种类相对比较丰 富(3年累计观测到103种, 占54.5\%), 所以多样性指
数 $\left(H^{\prime}=3.93\right)$ 和均匀度指数 $(J=0.85)$ 较高。农田和果 园生境的三角潭样线由于生境单一, 蝴蝶物种数目 相对较少(3年累计观测到97种，占51.3\%)。由于农 田季节性的耕作，导致东方菜粉蝶(Pieris canidia) (3年累计观测到 371 只，占 5.3\%)、宽边黄粉蝶 (Eurema hecabe) (3年累计观测到149只，占2.2\%) 等个体数目的季节性激增, 所以该观测样线多样性 指数 $\left(H^{\prime}=3.22\right)$ 和均匀度指数 $(J=0.70)$ 最低, 优势 度指数最高 $(D=0.09)$ 。 


\section{4 蝴蝶类群的时间动态}

由图2(a)可知, 不同年份所观测到的蝴蝶物种 数差异不明显, 5条样线单次观测物种最多的是 2016年9月的81种，单次观测物种最少的是 2017 年 4 月的45种。由图2(b)可知，同样的样线，不同年份所 观测到的蝴蝶个体数差异较大, 2016年5条样线6次 调查累计观测到的蝴蝶个体数(2,792只)要明显多于 2017年(2,009只)和2018年(2,145只), 这可能与 2017 年和2018年该保护区雨水较多有一定的关系。分析 2016年的数据发现, 从4月(233只)开始, 每次观测 到的蝴蝶数目逐渐增长, 到 9 月达到最高(686只), 10 月仍保持较高的水平 (670只), 这可能与该保护区的 气温、植物多样性及水文有一定的关系。总之, 齐 云山国家级自然保护区蝴蝶个体数从 4 月开始逐渐 增加, 6-7月基本稳定并维持到10月; 物种数在4-10 月基本稳定，具有较高的多样性指数。

\section{5 蝶类区系组成}

依据《中国蝶类志》(周尧, 1994) 将189种蝴蝶 分为东洋界、古北界、澳洲界和新北界(附录1)。东 洋界种类是优势类群, 总计183种, 占总种数的 $96.8 \%$, 其中蛱蝶科种类最多, 有 77 种, 占东洋界种 类的 $42.1 \%$; 其次是古北界种类，总计 46 种(其中只 在古北界分布的物种只有 5 种, 其余 41 种在东洋界 也有分布), 占总种数的 $24.3 \%$; 这说明齐云山国家 级自然保护区的蝴蝶区系组成以东洋区为绝对主 导的分布类型。

\section{3 讨论}

\section{1 生境对蝴蝶群落多样性的影响}

蝴蝶物种的分布规律及其多样性受自身的生

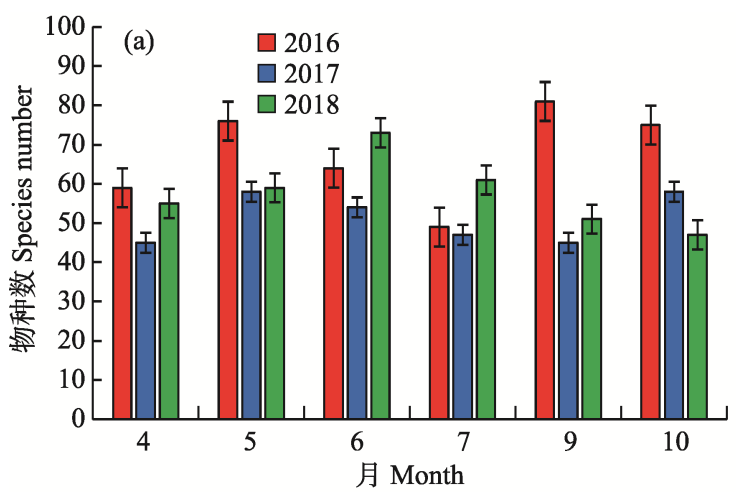

物学特性、寄主植物分布、外界非生物因素和人类 活动情况等多重因素影响, 其中非生物因素主要包 括气候条件、海拔高度、湿度、光照强度、林区郁 闭度等, 人类活动主要包括农药和除草剂的使用、 经济作物的轮作、野生植物的砍伐等。研究发现，在 影响蝴蝶分布的诸多因子中, 气候与植被尤为关键, 特别是气候变化对蝴蝶地理分布的影响最为显著 (Pamesan et al, 1999)。另外，据张宇军和房丽君 (2011)的研究发现, 地形是影响蝴蝶物种丰富度的 一个很重要的因子, 蝴蝶的密度和物种丰富度与地 形复杂度呈正相关关系，随着地形复杂度的升高而 逐渐升高。

齐云山国家级自然保护区的5条样线中，桐江 样线生境类型多样且没有太多的人类活动，所以该 样线3年观测到的蝴蝶个体数和物种丰富度均较高。 上十八垒样线植物多样性丰富，但是由于林区郁闭 度较高且受到季节性旅游业的影响，该样线物种丰 富度较好，而蝴蝶的个体数则相对较低。

\section{2 人类活动对蝴蝶群落多样性的影响}

研究发现, 特定生境下植物群落(尤其是蝴蝶 的寄主植物及蜜源植物)结构越复杂、生境类型越多 样、人类活动强度越小, 生境质量就越优越, 蝴蝶 的多样性就越高(王敏等, 2003)。齐云山国家级自然 保护区三角潭样线地处保护区外围，样线周边存在 大量农田和果园, 所以蝴蝶的密度和物种丰富度受 季节性农耕活动的影响比较明显; 因该样线自2017 年开始，每年对路边杂草杂灌清理2次(使用除草剂 或者人工砍伐), 所以该样线蝴蝶的密度和物种丰 富度均显著下降。

总之, 江西省齐云山国家级自然保护区因生境

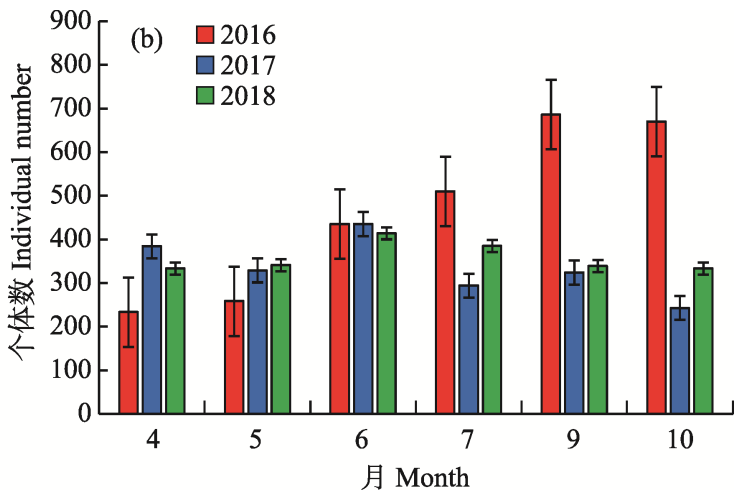

图2 齐云山国家级自然保护区不同年份蝴蝶物种数(a)和个体数(b)的时间动态图(平均值 \pm 标准差)

Fig. 2 Fluctuation of butterfly species (a) and individuals (b) in different years of the Qiyunshan National Nature Reserve (mean \pm $\mathrm{SD})$ 
类型多样、植物群落结构复杂、寄主植物丰富、气 候条件适宜等因素形成了较高的蝴蝶多样性。季节 性的农耕活动、除草剂农药的大量使用、路边杂草 杂灌等寄主植物的大量砍伐等人类活动破坏了蝴 蝶适宜生境, 威胁到蝴蝶的多样性及蝶类群落结构 的稳定性。研究表明良好的设计规划和合理的保护 措施便于保护和恢复蝴蝶类群赖以生存的生境, 是 保护蝴蝶物种多样性、保证蝴蝶资源可持续发展的 关键(Olga et al, 2019)。因此，建议对江西省齐云山 国家级自然保护区蝴蝶多样性的保护主要采取以 下措施：首先，要保护保护区及周边区域的植被多 样性, 尤其是蝴蝶寄主植物的多样性, 尽量减少除 草剂的使用及人工砍伐等人类活动; 其次, 减少旅 游开发对蝴蝶栖息地的破坏和分割并加强对当地 居民及游客的宣传教育, 使公众意识到蝴蝶资源所 受到的威胁及自然资源可持续发展的重要性; 最后, 需要科研工作者在现有调查的基础上对保护区内 蝴蝶资源及其寄主植物资源进一步深入研究, 制订 具体的保护措施。

\section{参考文献}

Berger WH, Parker FL (1970) Diversity of planktonic foraminifera in deep-sea sediments. Science, 168, 1345-1347.

Chen YL, Lin YL, Su MS, Zhang LP, Zhang Y, Chen HM (2019) Flora of macrofungal in Qiyun Mountain National Nature Reserve of Jiangxi. Journal of Fungal Research, 17, 26-34. (in Chinese with English abstract) [陈言柳, 林宇岗, 苏明声, 张林平, 张扬, 陈辉敏 (2019) 江西齐云山国家 级自然保护区大型真菌区系特征研究. 菌物研究, 17, 26-34.]

Chou I (1994) Monographia Rhopalocerorum Sinensium. Henan Science and Technology Press, Zhengzhou. (in Chinese) [周尧 (1994) 中国蝶类志. 河南科学技术出版 社, 郑州.]

Donkersley P, Rhodes G, Pickup RW, Jones KC, Wilson K (2014) Honeybee nutrition is linked to landscape composition. Ecology and Evolution, 4, 4195-4206.

Gu W, Ma L, Liu ZQ, Jiao Y, Wang LD, Zhang C, Sun H, Sun MO (2015) Diversity of butterflies in Liangshui Nature Reserve of Xiao Xing'an Mountains. Acta Ecologica Sinica, 35, 7387-7396. (in Chinese with English abstract) [顾伟, 马玲, 刘哲强, 焦玥, 王利东, 张琛, 孙虎, 孙美欧 (2015) 小兴安岭凉水自然保护区蝶类多样性. 生态学报, 35, 7387-7396.]

Hong XM, Ge XY, Li JL (2018) Butterfly diversity and its influencing factors in Saihanwula Nature Reserve. Biodiversity Science, 26, 590-600. (in Chinese with English abs- tract) [洪雪萌, 戈听宇, 李俊兰 (2018) 赛罕乌拉自然保 护区蝶类多样性及其影响因素. 生物多样性, 26, 590-600.]

Kitching RL, Orr AG, Thalib L, Mitchell H, Hopkins MS, Graham AW (2000) Moth assemblages as indicators of environmental quality in remnants of upland Australian rain forest. Journal of Applied Ecology, 37, 284-297.

Kremen C (1992) Assessing the indicator properties of species assemblages for natural areas monitoring. Ecological Applications, 2, 203-217.

Li JL, Pei HY, Liu DJ, Yang HS, Zhang YQ, Luo ZW (2011) Diversity of butterfly species in different habitats in Shenjiadian forest areas. Journal of Environmental Entomology, 33, 308-314. (in Chinese with English abstract) [李佳琳, 裴海英, 刘德江, 杨洪升, 张雨奇, 罗志文 (2011) 申家 店林区不同生境蝶类多样性调查. 环境昆虫学报，33, 308-314.]

Li M, Zhou HC, Tan JC, Wang P, Liu GH (2011) Butterfly species diversity and its conservation in Wuyunjie National Nature Reserve, Hunan Province of China. Chinese Journal of Applied Ecology, 22, 1585-1591. (in Chinese with English abstract) [李密, 周红春, 谭济才, 王鹏, 刘国华 (2011) 乌云界国家级自然保护区蝴蝶物种多样性及其保 护. 应用生态学报, 22, 1585-1591.]

Liu SQ, Xiang Y, Zhao X, Zhang YX (2017) New record of butterflies in Hunan Province. Journal of Jishou University (Natural Sciences Edition), 38(5), 77-79. (in Chinese with English abstract) [刘素群, 向颖, 赵欣, 张佑 祥 (2017) 湖南省蝶类新纪录. 吉首大学学报(自然科学 版), 38(5), 77-79.]

Liu XM, Guo YR, Liu RL (2010) The Comprehensive Scientific Investigation of the Qiyunshan National Nature Reserve, pp. 4-25. China Forestry Publishing House, Beijing. (in Chinese) [刘小明, 郭英荣, 刘仁林 (2010) 江 西齐云山自然保护区综合科学考察集, 4-25页. 中国林业 出版社, 北京.]

Ma FZ, Xu HG, Chen MM, Tong WJ, Wang CB, Cai L (2018) Progress in construction of China Butterfly Diversity Observation Network (China BON-Butterflies). Journal of Ecology and Rural Environment, 34, 27-36. (in Chinese with English abstract) [马方舟, 徐海根, 陈萌萌，童文君， 王晨涁, 蔡蕾 (2018) 全国蝴蝶多样性观测网络(China BON-Butterflies)建设进展. 生态与农村环境学报，34, 27-36.]

Ma KP, Liu YM (1994) Method for measuring the diversity of biological communities. I. Measurement methods of $\alpha$ diversity (Part 2). Chinese Biodiversity, 2, 231-239. (in Chinese) [马克平, 刘玉明 (1994) 生物群落多样性的测 度方法. I. $\alpha$ 多样性的测度方法(下). 生物多样性，2, 231-239.]

Mair L, Thomas CD, Anderson BJ, Fox R, Botham M, Hill JK (2012) Temporal variation in responses of species to four decades of climate warming. Global Change Biology, 18, 
2439-2447.

Márialigeti S, Tinya F, Bidló A, Ódor P (2016) Environmental drivers of the composition and diversity of the herb layer in mixed temperate forests in Hungary. Plant Ecology, 217, 549-563.

Maveety SA, Browne RA, Erwin TL (2013) Carabid beetle diversity and community composition as related to altitude and seasonality in Andean forests. Studies on Neotropical Fauna and Environment, 48(3), 165-174.

Mei J, Ran H, Yang TY, Xu QZ (2015) Species diversity of butterflies in Fanjing Mountain National Nature Reserve of Guizhou. Chinese Journal of Ecology, 34, 504-509. (in Chinese with English abstract) [梅杰, 再辉, 杨天友, 许勤 智 (2015) 贵州梵净山国家级自然保护区蝴蝶多样性. 生态学杂志, 34, 504-509.]

Nowicki P, Settele J, Henry PY, Woyciechowski M (2008) Butterfly monitoring methods: The ideal and the real world. Israel Journal of Ecology \& Evolution, 54, 69-88.

Ohwaki A, Kaneko Y, Ikeda H (2015) Seasonal variability in the response of ground beetles to a forest edge in a heterogeneous agricultural landscape in Japan. European Journal of Entomology, 112, 135-144.

Olga T, Vassiliki K, Maria P, Evangelos T, Sinos G (2019) Butterfly diversity along the urbanization gradient in a densely-built Mediterranean city: Land cover is more decisive than resources in structuring communities. Landscape and Urban Planning, 183, 79-87.

Pamesan C, Ryrholm N, Stefanescu C, Hill JK, Thomas CD, Descimon H, Huntley B, Kaila L, Kullberg J, Tammaru T, Tennent WJ, Thomas JA, Warren M (1999) Polew and shifts in geographical ranges of butterfly species associated with regional warming. Nature, 399, 579-583.

Pielou EC (1966) The measurement of diversity in different types of biological collections. Journal of Theoretical Biology, 13, 131-144.

Rands MRW, Adams WM, Bennun L, Butchart SHM, Clements A, Coomes D, Entwistle A, Hodge I, Kapos V, Scharlemann JPW (2010) Biodiversity conservation: Challenges beyond 2010. Science, 329, 1298-1303.

Samways MJ (2005) Insect Diversity Conservation. Cambridge University Press, Cambridge.

Shannon CE (1948) A mathematical theory of communication. Bell System Technical Journal, 27, 379-423, 623-656.

Siviter H, Brown MJF, Leadbeater E (2018) Sulfoxaflor exposure reduces bumblebee reproductive success. Nature, 561, 109-112.

Tsvetkov N, Samson-Robert O, Sood K, Patel HS, Malena DA, Gajiwala PH, Maciukiewicz P, Fournier V, Zayed A (2017) Chronic exposure to neonicotinoids reduces honey bee health near corn crops. Science, 356, 1395-1397.

Wang M, Huang GH, Fan XL, Xie GZ, Huang LS, Dai KY (2003) Species diversity of butterflies in Shimentai Nature Reserve, Guangdong. Biodiversity Science, 11, 441-453. (in Chinese with English abstract) [王敏, 黄国华, 范骁凌, 谢 国忠, 黄林生, 戴克元 (2003) 石门台自然保护区蝴蝶物 种多样性研究. 生物多样性, 11, 441-453.]

Wang XW, Müller J, An LL, Ji LZ, Liu Y, Wang XG, Hao ZQ (2014) Intra-annual variations in abundance and species composition of carabid beetles in a temperate forest in Northeast China. Journal of Insect Conservation, 18, 85-98.

Wu CS (2010) Fauna Sinica Insecta (Vol. 52): Lepidoptera, Pieridae. Science Press, Beijing. (in Chinese) [武春生 (2010) 中国动物志 昆虫纲 (第五十二卷): 鳞翅目, 粉蝶 科. 科学出版社, 北京.]

Xu HG, Cao MC, Wu Y, Cai L, Cao Y, Ding H, Cui P, Wu J, Wang Z, Le ZF, Lu XQ, Liu L, Li JQ (2017) Optimized monitoring sites for detection of biodiversity trends in China. Biodiversity and Conservation, 26, 1959-1971.

Yan H, Yuan XZ, Liu WP, Deng HL (2006) Butterfly diversity along a gradient of urbanization: Chongqing as a case study. Biodiversity Science, 14, 216-222. (in Chinese with English abstract) [晏华, 袁兴中, 刘文萍, 邓合黎 (2006) 城市化 对蝴蝶多样性的影响: 以重庆市为例生物多样性. 生物多 样性, 14, 216-222.]

You MS (1997) Conservation and utilization of the insect diversity in China. Chinese Biodiversity, 5, 135-141. (in Chinese with English abstract) [尤民生 (1997) 论我国昆 虫多样性的保护与利用. 生物多样性, 5, 135-141.]

Yuan JX, Hu HL, Xue GX (2015) Monograph of Butterflies in Jiangxi Jiulianshan National Nature Reserve. Heilongjiang Scientific and Technological Publishing House, Harbin. (in Chinese) [袁景西, 胡华林, 薛国喜 (2015) 江西九连山国 家级自然保护区蝴蝶. 黑龙江科技出版社, 哈尔滨.]

(责任编委: 白明 责任编辑: 黄祥忠)

\section{附录 Supplementary Material}

附录1 江西省齐云山国家级自然保护区蝴蝶物种名录

Appendix 1 The list of butterfly species in the Qiyunshan National Nature Reserve http://www.biodiversity-science.net/fileup/PDF/2019420-1.pdf 
黄敦元, 黄世贵, 王建皓, 李红英, 卖飞越, 张可, 朱祥龙, 马方舟 (2020) 人齐云山国家级自然保护区蝴蝶 群落多样性, 28 (8):958-964. http://www.biodiversity-science.net/CN/10.17520/biods.2019420

附录1 江西省齐云山国家级自然保护区蝴蝶物种名录。1: 上十八垒; 2: 下十八垒; 3: 桐江; 4: 鸡公坝; 5: 三角潭。

Appendix 1 The list of butterfly species in the Qiyunshan National Nature Reserve. 1, Shangshibalei; 2, Xiashibalei, 3, Tongjiang; 4, Jigongba; 5, Sanjiaotan.

\begin{tabular}{|c|c|c|c|c|c|c|c|c|c|}
\hline \multirow{2}{*}{$\begin{array}{l}\text { 序号 } \\
\text { No. }\end{array}$} & \multirow{2}{*}{$\begin{array}{l}\text { 科 } \\
\text { Family }\end{array}$} & \multirow{2}{*}{$\begin{array}{l}\text { 属 } \\
\text { Genus }\end{array}$} & \multirow{2}{*}{$\begin{array}{l}\text { 种 } \\
\text { Species }\end{array}$} & \multicolumn{5}{|c|}{ 物种数 Species number } & \multirow{2}{*}{$\begin{array}{l}\text { 合计 } \\
\text { Tota }\end{array}$} \\
\hline & & & & 1 & 2 & 3 & 4 & 5 & \\
\hline 1 & 凤蝶科 & 凤蝶属 Papilio & 1 巴黎翠凤蝶 P. paris & 2 & 3 & 14 & 30 & 17 & 66 \\
\hline 2 & Papilionidae & & 2 碧翠凤蝶 P. bianor & 3 & 3 & 14 & 16 & 9 & 45 \\
\hline 3 & & & 3 柑橘凤蝶 $P$. xuthus & & 1 & 6 & 1 & 48 & 56 \\
\hline 4 & & & 4 金凤蝶 $P . \quad$ machaon & & & & & 4 & 4 \\
\hline 5 & & & 5 蓝美凤蝶 $P$. protenor & 25 & 24 & 26 & 27 & 55 & 157 \\
\hline 6 & & & 6 窄斑翠凤蝶 $P$. arcturus & 3 & & 2 & 2 & & 7 \\
\hline 7 & & & 7 穹翠凤蝶 P. dialis & 3 & & 4 & 3 & & 10 \\
\hline 8 & & & 8 玉斑美凤蝶 $P$. helenus & 1 & 4 & 24 & 20 & 12 & 61 \\
\hline 9 & & & 9 玉带美凤蝶 P. polytes & 1 & 5 & 18 & 6 & 8 & 38 \\
\hline 10 & & 斑凤蝶属 Chilasa & 1 褐斑凤蝶 C. agestor & & & 6 & & & 6 \\
\hline 11 & & 钩凤蝶属 Meandrusa & 1 褐钩凤蝶 $M$. sciron & 1 & 2 & 8 & & & 11 \\
\hline 12 & & 青凤蝶属 Graphium & 1 宽带青凤蝶 G.cloanthus & 8 & 18 & 16 & 25 & 7 & 74 \\
\hline 13 & & & 2 青凤蝶 G. sarpedon & 28 & 50 & 29 & 35 & 25 & 167 \\
\hline 14 & & & 3 碎斑青凤蝶 G. chironides & 15 & 89 & 55 & 32 & 7 & 198 \\
\hline 15 & & & 4 统帅青凤蝶 Gagamemnon & & 1 & 26 & & 3 & 30 \\
\hline 16 & & 珠凤蝶属 Pachliopta & 1 红珠凤蝶 P. aristolochiae & & 4 & 9 & & 1 & 14 \\
\hline 17 & & 鹿凤蝶属 Byasa & 1 灰线球凤蝶 B. mencius & & & 1 & & 1 & 2 \\
\hline 18 & & & 2 㢌凤蝶 B.alcinous & & & 24 & 5 & & 29 \\
\hline 19 & & & 3 长尾柕凤蝶 B. impediens & & & 2 & & & 2 \\
\hline 20 & & 裳凤蝶属 Troides & 1 金裳凤蝶 T. aeacus & & & 2 & & 2 & 4 \\
\hline 21 & 粉蝶科 & 绢粉蝶属 Aporia & 1 大翅绢粉蝶 A. largeteaui & & & 23 & & 37 & 60 \\
\hline 22 & Pieridae & & 2 小檗绢粉蝶 A. hippia & & 3 & & & & 3 \\
\hline 23 & & 粉蝶属 Pieris & 1 菜粉蝶 P. rapae & 3 & 2 & 12 & 13 & 39 & 69 \\
\hline 24 & & & 2 东方菜粉蝶 P. canidia & 24 & 21 & 54 & 61 & 211 & 371 \\
\hline 25 & & 黄粉蝶属 Eurema & 1 尖角黄粉蝶 E. laeta & 14 & 23 & 37 & 15 & 15 & 104 \\
\hline 26 & & & 2 檗黄粉蝶 E. blanda & & 13 & 16 & 29 & 10 & 68 \\
\hline 27 & & & 3 宽边黄粉蝶 E. hecabe & 22 & 21 & 17 & 34 & 55 & 149 \\
\hline 28 & & 豆粉蝶属 Colias & 1 东亚豆粉蝶 C. poliographus & 1 & & & & & 1 \\
\hline 29 & & 迁粉蝶属 Catopsilia & 1 梨花迁粉蝶 C.pyranthe & & 1 & 1 & & & 2 \\
\hline 30 & & & 2 迁粉蝶 C. pomona & & & & & 3 & 3 \\
\hline 31 & & 飞龙粉蝶属 Talbotia & 1 飞龙粉蝶 T. naganum & 1 & 29 & 55 & 8 & 6 & 99 \\
\hline 32 & & 方粉蝶属 Dercas & 1 黑角方粉蝶 D. lycorias & & 3 & 13 & 4 & 2 & 22 \\
\hline 33 & & 园粉蝶属 Cepora & 1 黑脉圆粉蝶 C. nerissa & 1 & & & & & 1 \\
\hline 34 & & 橙粉蝶属 Ixias & 1 橙粉蝶 I. pyrene & & & & & 1 & 1 \\
\hline 35 & & 斑粉蝶属 Delias & 1 艳妇斑粉蝶 D. belladonna & 12 & 16 & 23 & & 1 & 52 \\
\hline 36 & 灰蝶科 & 波蚬蝶属 Zemeros & 1 波蚬蝶 Z. flegyas & & & 18 & 2 & 3 & 23 \\
\hline 37 & Hesperiidae & 尾蚬蝶属 Dodona & 1 彩斑尾蚬蝶 D. maculosa & & & & 1 & & 1 \\
\hline 38 & & 白蚬蝶属 Stiboges & 1 白蚬蝶 S. nymphidia & 18 & 18 & 4 & 21 & 7 & 68 \\
\hline
\end{tabular}


黄敦元, 黄世贵, 王建皓, 李红英, 赎飞越, 张可, 朱祥龙, 马方舟 (2020) 人齐云山国家级自然保护区蝴蝶 群落多样性, 28 (8):958-964. http://www.biodiversity-science.net/CN/10.17520/biods.2019420

\begin{tabular}{|c|c|c|c|c|c|c|c|c|c|}
\hline \multirow{2}{*}{$\begin{array}{l}\text { 序号 } \\
\text { No. }\end{array}$} & \multirow{2}{*}{$\begin{array}{l}\text { 科 } \\
\text { Family }\end{array}$} & \multirow{2}{*}{$\begin{array}{l}\text { 属 } \\
\text { Genus }\end{array}$} & \multirow{2}{*}{$\begin{array}{l}\text { 种 } \\
\text { Species }\end{array}$} & \multicolumn{5}{|c|}{ 物种数 Species number } & \multirow{2}{*}{$\begin{array}{l}\text { 合计 } \\
\text { Total }\end{array}$} \\
\hline & & & & 1 & 2 & 3 & 4 & 5 & \\
\hline 39 & & 褐蚬蝶属 Abisara & 1 白带褐蚬蝶 A. fylloideszz & 1 & 1 & 1 & & & 3 \\
\hline 40 & & & 2 黄带褐蚬蝶 A. fylla & & & 12 & & & 12 \\
\hline 41 & & & 3 蛇目褐蚬蝶 A. echerius & & & 9 & & 1 & 10 \\
\hline 42 & & 尾蚬蝶属 Dodona & 1 斜带缺尾蚬蝶 D. ouida & 1 & 3 & & & & 4 \\
\hline 43 & & & 2 大斑尾蚬蝶 D. egeon & & 1 & & 1 & & 2 \\
\hline 44 & & 娜灰蝶属 Nacaduba & 1 古楼娜灰蝶 $N$. kurava & 22 & 3 & 45 & 24 & 27 & 121 \\
\hline 45 & & 妩灰蝶属 Udara & 1 白斑妩灰蝶 U.albocaerulea & 11 & 4 & 7 & 25 & 19 & 66 \\
\hline 46 & & & 1 珍贵妩灰蝶 $U$. dilrcta & 5 & 3 & 13 & 3 & 1 & 25 \\
\hline 47 & & 蚜灰蝶属 Taraka & 1 蚜灰蝶 T. hamada & 2 & 5 & 16 & 10 & 20 & 53 \\
\hline 48 & & 生灰蝶属 Sinthusa & 1 生灰蝶 S. chandrana & 2 & & 17 & 17 & 18 & 54 \\
\hline 49 & & 灰蝶属 Spindasis & 1 银线灰蝶 S. lohita & & & 31 & 15 & 11 & 57 \\
\hline 50 & & 琉璃灰蝶属 Celastrina & 1 琉璃灰蝶 C. argiolus & & & 2 & & & 2 \\
\hline 51 & & 银灰蝶属 Curetis & 1 尖翅银灰蝶 C. acuta & 16 & 4 & 16 & 8 & & 44 \\
\hline 52 & & 玛灰蝶属 Mahathaio & 1 玛灰蝶 M. ameria & 4 & & 4 & & & 8 \\
\hline 53 & & 玄灰蝶属 Tongeia & 1 玄灰蝶 $T$. fischeri & & & 4 & & & 4 \\
\hline 54 & & & 2 波太玄灰蝶 T. potanini & & 10 & 1 & 24 & & 35 \\
\hline 55 & & 钮灰蝶属 Acytolepis & 1 钮灰蝶 A. puspa & & 3 & & & 1 & 4 \\
\hline 56 & & 亮灰蝶属 Lampides & 1 亮灰蝶 L. boeticus & & & 1 & & 1 & 2 \\
\hline 57 & & 彩灰蝶属 Heliophorus & 1 浓紫彩灰蝶 H. ila & 1 & 3 & 2 & & 2 & 8 \\
\hline 58 & & 玳灰蝶属 Deudorix & 1 淡黑玳灰蝶 D. rapaloides & 1 & & & & & 1 \\
\hline 59 & & 绿灰蝶属 Artipe & 1 绿灰蝶 A. eryx & 17 & & 11 & & 1 & 29 \\
\hline 60 & & 棕灰蝶属 Euchrysops & 1 棕灰蝶 E. cnejus & & & 1 & & & 1 \\
\hline 61 & & 酢浆灰蝶属 Pseudozizeeria & 1 酢浆灰蝶 P. maha & 43 & 101 & 88 & 102 & 82 & 416 \\
\hline 62 & & 雅灰蝶属 Jamides & 1 雅灰蝶 J. bochus & 2 & 8 & 1 & 5 & & 16 \\
\hline 63 & & 丸灰蝶属 Pithecops & 1 黑丸灰蝶 $P$. corvus cornix & & & 4 & 2 & & 6 \\
\hline 64 & & 燕灰蝶属 Rapala & 1 燕灰蝶 $R$. varuna & 3 & 2 & & & & 5 \\
\hline 65 & & 鹿灰蝶属 Loxura & 1 鹿灰蝶 L. atymnus & & 1 & 1 & & & 2 \\
\hline 66 & 蛱蝶科 & 翟眼蝶属 Ypthima & 1 翟眼蝶 Y.motschulskyi & 26 & 33 & 65 & 107 & 80 & 311 \\
\hline 67 & Nymphalidae & & 2 大波蒦眼蝶 Y.tappana & & 11 & 9 & 5 & & 25 \\
\hline 68 & & & 3 拟四眼篗眼蝶 Y.imitans & 1 & 12 & 47 & 78 & 56 & 194 \\
\hline 69 & & & 4 密纹翟眼蝶 Y.multistriata & 1 & 4 & 24 & 34 & 7 & 70 \\
\hline 70 & & 斑眼蝶属 Penthema & 1 白斑眼蝶 P. adelma & 52 & 45 & 37 & 19 & 4 & 157 \\
\hline 71 & & 眉眼蝶属 Mycalesis & 1 小眉眼蝶 M. mineus & 11 & 6 & & 9 & & 26 \\
\hline 72 & & & 2 拟稻眉眼蝶 M. gotama & & 2 & 19 & & 2 & 23 \\
\hline 73 & & & 3 僧袈眉眼蝶 M. sangaica & 4 & 6 & 21 & 8 & 1 & 40 \\
\hline 74 & & & 4 稻眉眼蝶 M. gotama & 9 & 20 & 30 & 13 & 8 & 80 \\
\hline 75 & & 黛眼蝶属 Lethe & 1 曲纹黛眼蝶 L. chandica & 10 & 13 & 14 & 7 & 32 & 76 \\
\hline 76 & & & 2 玉带黛眼蝶 L. confusa & 24 & 5 & 6 & 5 & 9 & 49 \\
\hline 77 & & & 3 连纹黛眼蝶 L. syrcis & 39 & 78 & 148 & 31 & 8 & 304 \\
\hline 78 & & & 4 宽带黛眼蝶 L. helena & 7 & 4 & 2 & 4 & & 17 \\
\hline 79 & & & 5 蛇神黛眼蝶 L. satyrina & 1 & 7 & 2 & 9 & & 19 \\
\hline
\end{tabular}


黄敦元, 黄世贵, 王建皓, 李红英, 赎飞越, 张可, 朱祥龙, 马方舟 (2020) 人齐云山国家级自然保护区蝴蝶 群落多样性, 28 (8):958-964. http://www.biodiversity-science.net/CN/10.17520/biods.2019420

\begin{tabular}{|c|c|c|c|c|c|c|c|c|c|}
\hline \multirow{2}{*}{$\begin{array}{l}\text { 序号 } \\
\text { No. }\end{array}$} & \multirow{2}{*}{$\begin{array}{l}\text { 科 } \\
\text { Family }\end{array}$} & \multirow{2}{*}{$\begin{array}{l}\text { 属 } \\
\text { Genus }\end{array}$} & \multirow{2}{*}{$\begin{array}{l}\text { 种 } \\
\text { Species }\end{array}$} & \multicolumn{5}{|c|}{ 物种数 Species number } & \multirow{2}{*}{$\begin{array}{l}\text { 合计 } \\
\text { Total }\end{array}$} \\
\hline & & & & 1 & 2 & 3 & 4 & 5 & \\
\hline 80 & & & 6 深山黛眼蝶 L. lanaris & 13 & 1 & 6 & 9 & & 29 \\
\hline 81 & & & 7 棕褐黛眼蝶 L.christophi & & 4 & & 1 & & 5 \\
\hline 82 & & & 8 紫线黛眼蝶 L.violaceopicta & 1 & & & & & 1 \\
\hline 83 & & & 9 白带黛眼蝶 L.confusa & 4 & 6 & 22 & 20 & 22 & 74 \\
\hline 84 & & 荫眼蝶属 Neope & 1 桐木荫眼蝶 $N$. contrasta & 9 & 61 & 34 & 2 & 15 & 121 \\
\hline 85 & & & 2 布莱荫眼蝶 N. bremeri & 18 & 13 & 29 & 5 & 25 & 90 \\
\hline 86 & & & 3 蒙链荫眼蝶 N.muirheadi & 31 & 12 & 19 & 44 & 10 & 116 \\
\hline 87 & & 古眼蝶属 Palaeonympha & 1 古眼蝶 P. opalina & 2 & & & 3 & & 5 \\
\hline 88 & & 暮眼蝶属 Melanitis & 1 睇暮眼蝶 $M$. phedima & 1 & & & & & 1 \\
\hline 89 & & 丽眼蝶属 Mandarinia & 1 蓝斑丽眼蝶 M. regalis & 3 & 7 & 5 & 1 & & 16 \\
\hline 90 & & 尾蛱蝶属 Polyura & 1 忘忧尾蛱蝶 P. nepenthes & 1 & 34 & 51 & 1 & 22 & 109 \\
\hline 91 & & & 2 二尾蛱蝶 $P . \quad$ narcaea & 14 & 39 & 43 & 14 & 21 & 131 \\
\hline 92 & & & 3 大二尾蛱蝶 P. eudamippus & & 3 & 6 & 6 & 19 & 34 \\
\hline 93 & & 环蛱蝶属 Neptis & 1 小环蛱蝶 N. sappho & 40 & 22 & 18 & 44 & 9 & 133 \\
\hline 94 & & & 2 中环蛱蝶 N. hylas & & 1 & 24 & 17 & 42 & 84 \\
\hline 95 & & & 3 卡环蛱蝶 N. cartica & & 1 & & & & 1 \\
\hline 96 & & & 4 玛环蛱蝶 N. manasa & 1 & & 4 & 1 & & 6 \\
\hline 97 & & & 5 阿环蛱蝶 N. ananta & & & & 6 & & 6 \\
\hline 98 & & & 6 耶环蛱蝶 N. yerburii & 5 & & 5 & & 1 & 11 \\
\hline 99 & & & 7 弥环蛱蝶 N. miah & 2 & 2 & 8 & 30 & 18 & 60 \\
\hline 100 & & & 8 珂环蛱蝶 N. clinia & & 2 & 1 & 5 & & 8 \\
\hline 101 & & & 9 娑环蛱蝶 $N$. soma & 2 & & & & & 2 \\
\hline 102 & & & 10 啡环蛱蝶 N. philyra & & 4 & 1 & 2 & 7 & 14 \\
\hline 103 & & & 11 链环蛱蝶 N. pryeri & 2 & 1 & 1 & & & 4 \\
\hline 104 & & & 12 断环蛱蝶 N. sankara & & & 3 & 1 & & 4 \\
\hline 105 & & 带蛱蝶属 Athyma & 1 六点带蛱蝶 A. punctata & & 1 & & 1 & & 2 \\
\hline 106 & & & 2 玉杵带蛱蝶 A. jina & 11 & 3 & 5 & 2 & 12 & 33 \\
\hline 107 & & & 3 玄珠带蛱蝶 A.perius & & & & & 7 & 7 \\
\hline 108 & & & 4 离斑带蛱蝶 $A$. ranga & & 2 & & & 1 & 3 \\
\hline 109 & & & 5 孤斑带蛱蝶 A. zeroca & & & & & 1 & 1 \\
\hline 110 & & & 6 相思带蛱蝶 A. nefte & & & 2 & & & 2 \\
\hline 111 & & & 7 珠履带蛱蝶 A. asura & 3 & 4 & 5 & & & 12 \\
\hline 112 & & & 8 新月带蛱蝶 A. selenophora & & 2 & 2 & & & 4 \\
\hline 113 & & & 9 虬眉带蛱蝶 A. opalina & & & 1 & & & 1 \\
\hline 114 & & 绢蛱蝶属 Calinaga & 1 大卫绢蛱蝶 C. davidis & & & & & 1 & 1 \\
\hline 115 & & 电蛱蝶属 Dichorragia & 1 电蛱蝶 D. nesimachus & 1 & 1 & 5 & & 11 & 18 \\
\hline 116 & & 翠蛱蝶属 Euthalia & 1 矛翠蛱蝶 E. aconthea & & & 1 & & & 1 \\
\hline 117 & & & 2 西藏翠蛱蝶 E. thibetana & 22 & 5 & 5 & 15 & & 47 \\
\hline 118 & & & 3 珀翠蛱蝶 E. pratti & & 1 & 1 & & & 2 \\
\hline 119 & & & 4 黄翅翠蛱蝶 E. kosempona & 12 & & 2 & 1 & & 15 \\
\hline 120 & & & 5 绿裙边翠蛱蝶 E. niepelti & & & 3 & 3 & & 6 \\
\hline
\end{tabular}


黄敦元, 黄世贵, 王建皓, 李红英, 卖飞越, 张可, 朱祥龙, 马方舟 (2020) 人齐云山国家级自然保护区蝴蝶

群落多样性, 28 (8):958-964. http://www.biodiversity-science.net/CN/10.17520/biods.2019420

\begin{tabular}{|c|c|c|c|c|c|c|c|c|c|}
\hline \multirow{2}{*}{$\begin{array}{l}\text { 序号 } \\
\text { No. }\end{array}$} & \multirow{2}{*}{$\begin{array}{l}\text { 科 } \\
\text { Family }\end{array}$} & \multirow{2}{*}{$\begin{array}{l}\text { 属 } \\
\text { Genus }\end{array}$} & \multirow{2}{*}{$\begin{array}{l}\text { 种 } \\
\text { Species }\end{array}$} & \multicolumn{5}{|c|}{ 物种数 Species number } & \multirow{2}{*}{$\begin{array}{l}\text { 合计 } \\
\text { Total }\end{array}$} \\
\hline & & & & 1 & 2 & 3 & 4 & 5 & \\
\hline 121 & & 丝蛱蝶属 Cyrestis & 1 网丝蛱蝶 C. thyodamas & 11 & 15 & 18 & 5 & & 49 \\
\hline 122 & & 红蛱蝶属 Vanessa & 1 大红蛱蝶 V. indica & & 3 & 1 & 1 & 9 & 14 \\
\hline 123 & & 福蛱蝶属 Fabriciana & 1 灿福蛱蝶 F. adippe & & & 1 & & & 1 \\
\hline 124 & & 锯蛱蝶属 Cethosia & 1 红锯蛱蝶 C. biblis & & & 34 & 2 & & 36 \\
\hline 125 & & 白蛱蝶属 Helcyra & 1 傲白蛱蝶 $H$. superba & & 2 & 1 & 2 & 12 & 17 \\
\hline 126 & & & 2 银白蛱蝶 $H$. subalba & & & & 5 & & 5 \\
\hline 127 & & 眼蛱蝶属 Junonia & 1 钩翅眼蛱蝶 J. iphita & 1 & & & & 9 & 10 \\
\hline 128 & & & 2 美眼蛱蝶 J. almana & 23 & 9 & 32 & 13 & 19 & 96 \\
\hline 129 & & & 3 翠蓝眼蛱蝶 $J$. orithya & & & & 1 & 2 & 3 \\
\hline 130 & & 银豹蛱蝶属 Childrena & 1 银豹蛱蝶 C. childreni & & 2 & & & 2 & 4 \\
\hline 131 & & 枯叶蛱蝶属 Kallima & 1 枯叶蛱蝶 K. inachus & & & & 1 & & 1 \\
\hline 132 & & 青豹蛱蝶属 Damora & 1 青豹蛱蝶 D. sagana & 9 & 6 & 16 & 17 & 16 & 64 \\
\hline 133 & & 线蛱蝶属 Parathyma & 1 残锷线蛱蝶 $P$. sulpitia & 1 & 4 & 13 & 12 & 22 & 52 \\
\hline 134 & & 饰蛱蝶属 Stibochiona & 1 素饰蛱蝶 S. nicea & 3 & & 3 & & & 6 \\
\hline 135 & & 邚蛱蝶属 Abrota & 1 邚蛱蝶 A. ganga & & & & 1 & & 1 \\
\hline 136 & & 琉璃蛱蝶属 Kaniska & 1 琉璃蛱蝶 $K$. canace & 1 & 2 & & & & 3 \\
\hline 137 & & 帅蛱蝶属 Sephisa & 1 黄帅蛱蝶 S. princeps & 2 & 1 & & & & 3 \\
\hline 138 & & 钩蛱蝶属 Polygnia & 1 黄钩蛱蝶 P. aureum & 2 & & 3 & & 15 & 20 \\
\hline 139 & & 盛蛱蝶属 Symbrenthia & 1 散纹盛蛱蝶 S. liaea & 6 & & 8 & 11 & & 25 \\
\hline 140 & & 豹蛱蝶属 Argynnis & 1 斐豹蛱蝶 A. hyperbius & 4 & 36 & 49 & 21 & 59 & 169 \\
\hline 141 & & 菲蛱蝶属 Phaedyma & 1 蔼菲蛱蝶 P. aspasia & & & & 2 & 3 & 5 \\
\hline 142 & & 串珠环蝶属 Faunis & 1 灰翅串珠环蝶 F. aerope & 1 & & & & & 1 \\
\hline 143 & & 纹环蝶属 Aemona & 1 纹环蝶 A. amathusia & & & 1 & 4 & & 5 \\
\hline 144 & & 箭环蝶属 Stichophthalma & 1 箭环蝶 S. louisa & 37 & 37 & 38 & 31 & & 143 \\
\hline 145 & & 喙蝶属 Libythea & 1 朴喙蝶 L. celtis & & & & 4 & & 4 \\
\hline 146 & & 珍蝶属 Acraea & 1 亘麻珍蝶 A. issoria & 2 & 27 & 26 & 18 & 15 & 88 \\
\hline 147 & & 弄蝶属 Hasora & 1 无趾弄蝶 H. anura & 9 & & & 3 & & 12 \\
\hline 148 & 并蝶枓 & 长标弄蝶属 Telicota & 1 长标弄蝶 T. colon & 1 & & & 5 & & 6 \\
\hline 149 & & & 2 红翅长标弄蝶 T. ancilla & & & 19 & 2 & 2 & 23 \\
\hline 150 & & & 3 黄纹长标弄蝶 $T$. ohara & & & 1 & & & 1 \\
\hline 151 & & & 4 紫翅长标弄蝶 T. linna & & & 4 & & 1 & 5 \\
\hline 152 & & & 5 黑脉长标弄蝶 $T$. linna & & & & & 1 & 1 \\
\hline 153 & & 锷弄蝶属 Aeromachus & 1 小锷弄蝶 A.nanus & 2 & & 1 & 8 & 4 & 15 \\
\hline 154 & & & 2 河伯锷弄蝶 A. inachus & & & 2 & 1 & & 3 \\
\hline 155 & & 黄室弄蝶属 Potanthus & 1 宽纹黄室弄蝶 P. pava & 1 & & & & & 1 \\
\hline 156 & & & 2 曲纹黄室弄蝶 P. flavus & & 1 & 3 & & & 4 \\
\hline 157 & & & 3 黄斑弄蝶 $P$. confucius & & & & 1 & 2 & 3 \\
\hline 158 & & & 4 断纹黄室弄蝶 P.trachalus & 3 & & & & & 3 \\
\hline 159 & & 白弄蝶属 Abraximorpha & 1 白弄蝶 A. davidii & 2 & 6 & & 2 & 2 & 12 \\
\hline 160 & & 酣弄蝶属 Halpe & 1 地藏酣弄蝶 H. dizangpusa & 2 & 1 & & & & 3 \\
\hline
\end{tabular}


黄敦元, 黄世贵, 王建皓, 李红英, 赎飞越, 张可, 朱祥龙, 马方舟 (2020) 人齐云山国家级自然保护区蝴蝶 群落多样性, 28 (8):958-964. http://www.biodiversity-science.net/CN/10.17520/biods.2019420

\begin{tabular}{|c|c|c|c|c|c|c|c|c|c|}
\hline \multirow{2}{*}{$\begin{array}{l}\text { 序号 } \\
\text { No. }\end{array}$} & \multirow{2}{*}{$\begin{array}{l}\text { 科 } \\
\text { Family }\end{array}$} & \multirow{2}{*}{$\begin{array}{l}\text { 属 } \\
\text { Genus }\end{array}$} & \multirow{2}{*}{$\begin{array}{l}\text { 种 } \\
\text { Species }\end{array}$} & \multicolumn{5}{|c|}{ 物种数 Species number } & \multirow{2}{*}{$\begin{array}{l}\text { 合计 } \\
\text { Total }\end{array}$} \\
\hline & & & & 1 & 2 & 3 & 4 & 5 & \\
\hline 161 & & 绿弄蝶属 Choaspes & 1 绿弄蝶 C. benjaminii & 4 & 4 & 8 & 2 & 3 & 21 \\
\hline 162 & & & 2 半黄绿弄蝶 C. hemixanthus & 1 & & & & 1 & 2 \\
\hline 163 & & 袖弄蝶属 Notocrypta & 1 曲纹袖弄蝶 N. curvifascia & & & 2 & 1 & & 3 \\
\hline 164 & & & 2 宽纹袖弄蝶 N. feisthamelii & & & 5 & 4 & & 9 \\
\hline 165 & & 稻弄蝶属 Parnara & 1 曲纹稻弄蝶 P. ganga & 1 & & & & & 1 \\
\hline 166 & & & 2 直纹稻弄蝶 $P$. guttata & & & 2 & & 2 & 4 \\
\hline 167 & & 裙弄蝶属 Tagiades & 1 滚边裙弄蝶 T. cohaerens & & & 5 & 8 & 1 & 14 \\
\hline 168 & & & 2 黑边裙弄蝶 T. menaka & 5 & & 7 & 3 & 2 & 17 \\
\hline 169 & & & 3 沾边裙弄蝶 T.litigiosa & & & & 1 & 4 & 5 \\
\hline 170 & & 讴弄蝶属 Onryza & 1 讴弄蝶 O. maga & 12 & 7 & 10 & 3 & 1 & 33 \\
\hline 171 & & 孔弄蝶属 Polytremis & 1 黄纹孔弄蝶 P. lubricans & & & 3 & 2 & 1 & 6 \\
\hline 172 & & & 2 刺纹孔弄蝶 P. zina & 1 & & & & & 1 \\
\hline 173 & & & 3 盒纹孔弄蝶 $P$. theca & 4 & 1 & 5 & 6 & 1 & 17 \\
\hline 174 & & 珂弄蝶属 Caltoris & 1 放踵珂弄蝶 C. cahira & 11 & & 10 & 10 & 2 & 33 \\
\hline 175 & & & 2 雀麦珂弄蝶 C.bromus & & & 1 & 1 & & 2 \\
\hline 176 & & 腌翅弄蝶属 Astictopterus & 1 腌翅弄蝶 A. jama & 2 & 5 & 11 & 10 & 10 & 38 \\
\hline 177 & & 大弄蝶属 Capila & 1 窗斑大弄蝶 C. penicillatu & & & 1 & & & 1 \\
\hline 178 & & 飒弄蝶属 Satarupa & 1 飒弄蝶 S. guttata & & 2 & 2 & & 1 & 5 \\
\hline 179 & & & 2 密纹飒弄蝶 S. monbeigi & 1 & 4 & 1 & 2 & & 8 \\
\hline 180 & & 蕉弄蝶属 Erionota & 1 黄斑蕉弄蝶 E. torus & 3 & & & & & 3 \\
\hline 181 & & 谷弄蝶属 Pelopidas & 1 隐纹谷弄蝶 P. mathias & & & 1 & & 2 & 3 \\
\hline 182 & & 旖弄蝶属 Isoteinon & 1 旖弄蝶 I. lamprospilus & 19 & 22 & 9 & 14 & & 64 \\
\hline 183 & & 陀弄蝶属 Thoressa & 1 南岭陀弄蝶 T.xiaoqingae & & & 3 & & & 3 \\
\hline 184 & & 斑弄蝶属 Ampittia & 1 钩形黄斑弄蝶 A.virgata & 13 & 8 & 2 & 16 & 8 & 47 \\
\hline 185 & & 姜弄蝶属 Udaspes & 1 姜弄蝶 U.folus & & & 1 & & & 1 \\
\hline 186 & & 籼弄蝶属 Borbo & 1 籼弄蝶 B. cinnara & 3 & & & & & 3 \\
\hline 187 & & 捷弄蝶属 Gerosis & 1 匪夷捷弄蝶 G. phisara & 1 & & & & & 1 \\
\hline 188 & & 豹弄蝶属 Thymelicus & 1 豹弄蝶 T. leonius & & & & 4 & & 4 \\
\hline 189 & & 赫弄蝶属 Ochlodes & 1 宽边赫弄蝶 $O$. ochracea & 1 & & & & & 1 \\
\hline 合计 & 5 & 106 & 189 & 905 & 1,189 & 1,945 & 1,449 & 1,458 & 6,946 \\
\hline
\end{tabular}

